\title{
A POTÊNCIA DA PEDAGOGIA FREIREANA NO CONTEXTO DO AUTORITARISMO NA EDUCAÇÃO BRASILEIRA
}

\author{
THE POWER OF FREIREAN PEDAGOGY IN THE CONTEXT OF \\ AUTHORITARIANISM IN BRAZILIAN EDUCATION
}

\author{
i Lúcio Gomes Dantas \\ Doutor em Educação \\ Universidade Católica de Brasília - UCB. \\ Brasília, DF- Brasil. \\ lucio@marista.edu.br \\ Lêda Gonçalves de Freitas \\ Doutora em Psicologia \\ Universidade Católica de Brasília - UCB. \\ Brasília, DF- Brasil. \\ ledag@p.ucb.br
}

\begin{abstract}
Resumo: O presente artigo tem como objetivo refletir sobre a potência da educação freireana frente ao ímpeto conservador autoritário do Brasil contemporâneo, expondo a ascensão do movimento reacionário em curso no Brasil. Para tanto, aponta como a história do Brasil é marcada pelo autoritarismo, em que se produziu a morte de milhares de povos originários; o processo de escravidão, que humilhou e vilipendiou centenas de outras pessoas; as ditaduras e a profunda desigualdade social encravada no país. Metodologicamente, tem-se um estudo exploratório que propicia uma reflexão sobre o legado da obra de Paulo Freire frente à afirmação de valores plurais e democráticos, necessários para realizar uma educação dialógica e problematizadora. Apresenta ainda elementos autoritários que já estão postos no contexto educacional brasileiro sob o espectro sombrio do perigo totalitário. Nesse sentido, este estudo ancorou-se nas luzes do pensamento arendtiano a respeito do sistema totalitário, reportando-se a um tempo de limitações de liberdade, de rigorosa perseguição política e de injustiça social. Entretanto, é pela indignação que se faz mover o mundo, sem perder a esperança de poder apreciá-lo na "boniteza" que a construção pedagógica, politicamente assumida, leva à liberdade. Assim, quando as raízes da educação são fincadas no horizonte da equidade, da amorosidade com as pessoas e da plena cidadania, a educação se torna humanizadora. Com isso a educação libertadora, sob a égide do pensamento de Paulo Freire, pode ancorar-se, sem sombra de dúvidas, em princípios éticos, para se alcançar os mais altos graus da escala do desenvolvimento humano.
\end{abstract}

Palavras-chave: autoritarismo; dialogicidade; educação brasileira; pedagogia freireana.

\begin{abstract}
This article aims to reflect on the power of Freirean education in face of the authoritarian conservative impetus of contemporary Brazil, exposing the rise of the reactionary movement underway in Brazil. To this end, it points out how the history of Brazil is marked by the authoritarianism, in which the death of thousands of native peoples took place; the process of slavery, which humiliated and vilipended hundreds of other people; the dictatorships and the deep social inequality embedded in the country. Methodologically, there is an exploratory study that provides a reflection on the legacy of the work of Paulo Freire in front of the statement of plural and democratic values, necessary to realize a dialogic and problematizing education. It also presents authoritarian elements that are already placed in the Brazilian educational context under the shadowy spectrum of totalitarian danger. In this sense, this study was anchored in the light of Arendtian thought about the totalitarian system, referring to a time of freedom limitations, rigorous political persecution, and social injustice. However, it is by indignation that the world is moved, without losing hope of being able to enjoy it in the beauty that the pedagogical construction, politically assumed, leads to freedom. Thus, when the roots of education are stuck in the horizon of equity, lovingness to people, and full citizenship, education becomes humanizing. With this, the liberating education, under the egis of the thought of Paulo Freire, can anchor itself, no doubt, on ethical principles to achieve the highest degrees of the human development scale.
\end{abstract}

Keywords: authoritarianism; dialogicity; brazilian education; freirean pedagogy.

Para citar - (ABNT NBR 6023:2018)

DANTAS, Lúcio Gomes; FREITAS, Lêda Gonçalves de. A potência da pedagogia freireana no contexto do autoritarismo na educação brasileira. Eccos - Revista Científica, São Paulo, n. 58, p. 1-16, e15685, jul./set. 2021. Disponível em: https://doi.org/10.5585/eccos.n58.15685. 


\section{Introdução}

A práxis educativa de Paulo Freire (1921-1997) expressa uma postura política favorável aos povos oprimidos. Nesse sentido, o legado freireano é o de uma "educação para a transformação", que significa educar o povo para que tenha a força da mudança e da libertação, conforme assevera o educador em sua obra Educação como Prática da Liberdade (FREIRE, 1967).

Freire, no conjunto das suas obras, sustenta que a educação não pode acontecer para a formação de um "homem-objeto", mas sim, do "homem-sujeito", não domesticado, não alienado, mas educado para a liberdade. Assim, o empenho de Paulo Freire como educador é o de conscientização das massas, do povo, alicerçado em uma prática educativa que provoque a reflexão e autorreflexão sobre o seu tempo histórico e o seu espaço (FREIRE, 1967, 2003b).

Em sua obra Pedagogia do Oprimido, escrita durante o seu exílio no Chile, por 16 anos, Freire expõe a sua pedagogia do oprimido, que é a pedagogia dos homens e mulheres empenhados na luta por liberdade. Para tanto, ensina que a libertação dos oprimidos tem raiz no saber dos oprimidos ao "saber-se oprimidos". Desse modo, a pedagogia do oprimido situase numa pedagogia humanista e libertadora, conforme destaca o educador, em que, primeiramente, se busca com os oprimidos desvendar a lógica da opressão, para que, na vida cotidiana, eles se comprometam com a liberdade e a construção da cidadania. Em seguida, com a consciência da opressão e, ao mesmo tempo, com a transformação da realidade, a pedagogia da libertação deixa de ser do oprimido e torna-se a pedagogia de todos os homens que estão em processo de permanente libertação (FREIRE, 2003b).

Nessa perspectiva, o exercício do pensar freireano, em sua pedagogia da libertação, não prega que o oprimido troque de lugar com o opressor, mas, a superação da contradição opressoroprimido. Conforme Freire, na experiência de ser oprimido há uma sedução pelos padrões de vida do opressor, um querer parecer com o opressor. A alienação imposta pelos saberes dos opressores, amplamente divulgados, faz com que os oprimidos assumam posturas passivas e aceitem forçosamente a sua exploração, um lugar historicamente construído pelas relações sociais de poder. Assim, a vociferação freireana é a de que os oprimidos tenham consciência da sua condição de opressão e de exploração (FREIRE, 2003b).

À vista disso, o educador Paulo Freire argumenta, com contundência, sobre a concepção "bancária" de educação, que atua de forma imobilista e desconhece os humanos como seres históricos. Nessa prática educativa, o educador leva os educandos a memorizar mecanicamente os conteúdos, ou seja, suas mentes são "vasilhas" que como recipientes precisam ser 
preenchidas. Nesse processo, o educador faz comunicados, efetivamente, e não se comunica com os educandos. Dessa forma, não há margem de ação para os educandos, a consciência é disciplinada, fundada para a obediência, o que favorece toda a opressão das elites escravocratas deste imenso país (FREIRE, 2003b).

Em contrapartida à educação bancária, Paulo Freire anuncia a educação problematizadora, a qual parte do caráter histórico dos seres humanos e da consciência de sua inconclusão. Isto é, na inconclusão consciente e na historicidade de ser SER humano existe uma busca por ser mais, que só se realiza no coletivo, na solidariedade. Dessa maneira, a educação problematizadora transgride os esquemas verticais da educação bancária, primeiramente por superar a contradição entre o educando e o educador, conforme revela Freire (2003b, p. 68): "ninguém educa ninguém, ninguém educa a si mesmo. Os homens se educam entre si, mediatizados pelo mundo". Em segundo lugar, o diálogo como alicerce da educação problematizadora, tendo em vista que dialogando, ao educar, o educador também se educa. Portanto, educador e educando são sujeitos no processo de educação como prática da liberdade, pois ação e reflexão caminham juntas em permanente interação.

Frente ao pensamento de Paulo Freire, o presente artigo objetiva refletir sobre a potência da educação freireana frente ao ímpeto conservador e autoritário que as elites econômicas e governamentais vêm apresentando ao Brasil contemporâneo. Assim sendo, busca apresentar a ascensão do movimento conservador e reacionário em curso no Brasil, sobretudo na educação, e procura focalizar a educação freireana como um caminho para a afirmação dos valores plurais e democráticos necessários para a construção de uma educação diversa, dialógica e humanamente solidária e inclusiva.

\section{Conservadorismo e autoritarismo no Brasil contemporâneo}

O autoritarismo brasileiro atravessa todo o processo de constituição do país, como bem aponta Schwarcz (2019) ao estudar o tema desde a invasão colonial, que provocou o genocídio dos povos originários; passando pela escravidão de milhões de pessoas arrancadas do seu lugar social no continente africano, com sua rica e valiosa cultura e saberes profundos; chegando aos dias atuais sob as mais funestas expressões, espalhando rastros de temor, dominação, destruição e violência.

A Independência do Brasil, em 1822, de acordo com Fernandes (1975), ainda que apresentasse uma dinâmica de transformação social, se configurou por seu caráter conservador traduzido pela manutenção da ordem social. O Estado Nacional que começou a ser desenhado 
constituiu-se de centros de poder, nas mãos de poucos. As elites oriundas da sociedade escravocrata passaram a gerir as atividades econômicas com o rompimento do estado de colônia. No entanto, o processo de produção e organização social pós-independência, fundamentalmente, logrou garantir o domínio dos senhores de engenho e a proteção de grupos privados.

De acordo com Fernandes (1975), o Estado Nacional que se formou foi organizado para proteger os fins econômicos e os interesses políticos dos estamentos senhoriais, que passam a moldar o recente Estado brasileiro. Há uma quebra com o Estado Colonial, mas, nestes trópicos não se desenvolveu uma concepção democrática de exercício do poder. A partir disso, floresce por aqui a dinâmica dos privilégios das elites, que atuam para preservar e fortalecer as estruturas socioeconômicas para manter o seu prestígio.

O fim da escravidão, em 1888, mobilizou diversos setores da sociedade brasileira à época, porém, os negros, que ao invés de receberem indenizações pelas atrocidades que passaram, foram abandonados à própria sorte sem qualquer política de inserção na sociedade republicana. A herança escravocrata, de acordo com Souza (2017), produziu a naturalização da miséria e do sofrimento, um ódio aos pobres, uma classificação absurda de quem é gente e quem não é.

Há no Brasil, ainda segundo Souza, uma construção de sub-humanidade calcada não no rompimento com o sistema escravocrata, mas em um país que constrói uma sociedade que reproduz ódios, que humilha e despreza os mais frágeis. Para o autor, esse imaginário foi herdado da escravidão. O ódio e a rejeição, por meio da aporofobia (CORTINA, 2017) aos pobres, são uma forma de singularidade das elites econômicas brasileiras. A sociedade aporofóbica expressa em seu seio a rejeição, o desprezo, a aversão, o temor e a depreciação à pessoa do pobre. Com isso coloca em risco valores essencialmente caros à democracia, tais como tolerância, respeito, dignidade da pessoa e generosidade. Elites que se apoderam da esfera pública e se aliam ao capital financeiro internacional moldam o poder em função dos seus interesses mesquinhos, colocando em risco os próprios governos democráticos.

Estudos realizados por Korybko (2018), Levitsky e Ziblatt (2018) e Mounk (2019) apontam para o perigo da destruição da democracia, uma vez que ela se encontra ameaçada com a implantação de governos com discursos exacerbadamente nacionalistas, populistas, e que abusam das mídias sociais e das tecnologias como espaços para camuflarem o autoritarismo, mas que querem também enfraquecer as intuições críticas. Querem criar, na prática, uma democracia sem direitos para desintegrar a população, com polarização ideológica. É o que se vê hoje no Brasil: a desintegração polarizada da população e circo do autoritarismo armado nas 
instituições. Há quem diga, como o renomado sociólogo Manuel Castells (2021), que o "Brasil já não é uma democracia".

Para a filósofa Marilena Chauí (2014), o autoritarismo do Brasil é estruturante da sua história econômica, política, cultural e educacional, tendo em vista que o país chega ao século XXI sem sequer efetivar princípios, não tão novos, como o liberalismo e o republicanismo. Além disso, apresenta-se com incapacidades para lidar com princípios básicos de igualdade perante a lei, como a Declaração dos Direitos Humanos de 1948, a organização das classes populares, as diversidades sexuais, étnicas e com os direitos das mulheres, entre outros direitos que assegurem a dignidade da pessoa humana.

A cidadania frente ao autoritarismo estruturante no país, para Chauí (2014), se apresenta como privilégio de classe, de modo que a concessão é sempre regulada pelas elites colonialistas e que disseminam o ódio aos pobres. As desigualdades sociais são naturalizadas e desenvolvidas por um processo de modernização que não rompeu com o imaginário escravocrata. Aguçam-se as relações de hierarquia, de mando e obediência, processos que atravessam as relações familiares, estatais e interpessoais.

Conforme Dias (2018) e Schwarcz (2019), a história do Brasil, desde a sua origem, é uma história de autoritarismo, racismo, mandonismo, corrupção, desigualdade social, violência e intolerância. Desde a invasão do Brasil por Pedro Álvares Cabral, o primeiro contato do país com a democracia foi no primeiro governo de Getúlio Vargas (1930-1937), sendo que o próprio Getúlio, por meio de um golpe de Estado, instituiu o Estado Novo (1937-1945). Outro momento de flerte com a democracia aconteceu no governo do presidente João Goulart (1961), que estimulou práticas de participação e divisão do poder até ser derrubado pela Ditatura Militar, que se instaurou com o Golpe de 1964.

Com o encerramento do período ditatorial, em 1985, um novo ciclo de democracia se iniciou, sendo mais uma vez interrompido, em 2016, com o Golpe Político-Jurídico-Midiático, que derrubou a presidenta Dilma Rousseff (DIAS, 2018). A intervenção autoritária de 2016 teve como alvo a democracia brasileira, tendo em vista que os períodos dos Governos Lula (2003-2010) e Dilma (2011-2016), em que pese o não rompimento com o poder do capitalismo financeiro nas definições dos rumos econômicos do país, constituíram momento e oportunidade de ampliação de direitos sociais e de maior participação dos movimentos populares na definição das políticas públicas do Brasil. Dessa forma, a elite do atraso, não conseguindo voltar ao governo pelas eleições democráticas, construiu uma narrativa utilizando-se de dispositivos democráticos para derrubar uma presidenta sem crime e voltar ao governo para, essencialmente, continuar a modernização que mantém seus privilégios e não rompe com a lógica da escravidão. 
Nesse contexto de fragilidade da democracia brasileira, a partir do Golpe de 2016, encontra-se a insatisfação das elites do atraso, as quais, contrariadas com os rumos políticos do país, sobretudo pela maior inclusão da população pobre e ampliação da visibilidade de setores marginalizados, como negros, mulheres e população LGBTQI+, iniciam a construção de um contexto caótico no qual movimentos como o do Movimento Brasil Livre (MBL) e o da Escola Sem Partido (ESP) produzem ampla popularização com suas teses conservadoras.

O MBL, de acordo com Silva (2018), surgiu em 2013 no contexto das mobilizações contra o governo de Dilma Rousseff. Suas teses conservadoras, defendidas amplamente nas redes sociais e em mobilizações de rua, englobam o patriotismo, o moralismo, as privatizações e o livre mercado. A atuação do movimento se destacou pela desconstrução das pautas sociais dos governos populares de Lula e Dilma, entre 2003 e 2016, com uma postura intransigente pela rejeição de políticas que visavam a inclusão social.

A ESP, de acordo com Cara (2016), é um movimento de inspiração internacional e tem como objetivos: a) "descontaminar" e "desmonopolizar" política e ideologicamente as escolas; b) respeitar a integridade moral dos estudantes; e, c) respeitar o direito dos pais de educar moralmente os seus filhos. Para Ximenes (2016), esse movimento quer limitar a liberdade de ensinar com vistas a barrar políticas públicas que visem trabalhar gênero, sexualidade e formação cidadã nas escolas brasileiras.

Abrucio (2016) assevera que os países com destaque nas avaliações internacionais não se orientam pelas proposições desse movimento. Salienta que as nações com destaque no Programa Internacional de Avaliação de Estudantes (PISA) têm como princípios a liberdade e criatividade de professores, juntamente com o controle dos resultados pedagógicos. Tais nações valorizam os docentes que estimulam a curiosidade e a consciência crítica de seus estudantes. Para o referido autor, a ESP estimula uma escola "Sem Sentido" ao criar um clima de perseguição aos professores e incitar uma educação "neutra", sem contexto e sem pluralidade.

Para os integrantes do movimento ESP, o educador Paulo Freire é o grande responsável pela doutrinação ideológica nas escolas. Desse modo, Gadotti (2016) compreende que a ESP, enquanto um movimento ideológico, de censura, é uma volta ao passado de 1964, do Golpe Militar que extinguiu o Programa Nacional de Alfabetização criado por Paulo Freire, o qual visava alfabetizar o povo a partir do seu contexto social.

Gadotti (2016) sustenta que a ESP é a total expressão de matar o pensamento crítico e a reflexão no espaço escolar. É a afirmação de uma pedagogia bancária. É tudo que Paulo Freire combateu, ou seja, uma escola doutrinária. O oposto de Freire, que sonhou e trabalhou por uma educação dialógica, reflexiva, crítica, cidadã e plural. 
Ademais, o conservadorismo no Brasil se aprofundou com a eleição do presidente Jair Messias Bolsonaro, em 2018. Observa-se que a base do "bolsonarismo", em curso no país, é a destruição dos direitos conquistados na Constituição Federal de 1988. Apoiada por uma retórica, de acordo com Araújo e Carvalho (2021), autoritária, ultraconservadora, militarista, violenta e reacionária, mobilizada cotidianamente para realizar uma guerra cultural em defesa de valores não democráticos e não liberais. Sobre esse Estado violento, vale salientar que, para Custódio (2019, p. 139), a violência do Estado não é apenas das armas, mas da "existência de moralidades hierarquizantes e excludentes. É a violência do cotidiano, que perpassa cada estágio da vida e existência” das pessoas.

Assim, direcionam-se os grandes problemas do país a dimensões morais e, ao mesmo tempo, na economia entrega-se o país a um mercado predador. Frente a isso, no ano dos cem anos do nascimento de Paulo Freire, 2021, faz-se necessário trazer a sua concepção de educação para repensar os dramas do Brasil contemporâneo.

\section{A atualidade da dialogicidade em Paulo Freire}

O movimento Escola Sem Partido tem como alvo central o educador Paulo Freire. Isto não é por acaso, dado que esse movimento representa o projeto educacional amplamente criticado por Freire, qual seja, a educação bancária. De fato, percebe-se que o referido movimento defende uma educação doutrinadora ao pregar a não dialogicidade, a negação da diversidade, da pluralidade e do pensar crítico nos contextos escolares. De acordo com essa pobre forma de pensar, a concepção de educação presente é a bancária, um tipo de educação que não apresenta margem para que os educandos ajam sobre o objeto a ser aprendido. Conforme Freire (2003b, p. 57) acentua, “[...] a concepção 'bancária' da educação, em que a única margem de ação que se oferece aos educandos é a de receberem os depósitos, guardá-los e arquivá-los".

Para debater com as narrativas contemporâneas que defendem uma educação desumanizada, sem o pensar crítico, sem amorosidade e diversidade, a educação dialógica freireana se apresenta como um caminho para nos humanizarmos e construirmos uma vida de solidariedade e de dignidade para todos os seres humanos. O diálogo, nesse sentido, é um fenômeno humano e se faz no trabalho da ação-reflexão (FREIRE, 2003b).

Diálogo é encontro. E no encontro os homens trazem suas palavras e pronunciam o mundo, se solidarizam, se escutam, refletem e agem no mundo e com o mundo. É ação que 
busca reconquistar os direitos retirados, negados pelo processo histórico de exclusão social, ensina Freire (2003b).

A dialogicidade acontece com o direito à palavra, meio de expressão, de exprimir-se no mundo. Com o exercício da palavra, os homens se apresentam ao mundo, se encontram com outros. Não um depósito de ideias de uns para outros, mas um refletir e agir conjunto em prol do bem comum. Para Freire (2003b), é assim que se cria a educação dialógica, só há possibilidade de diálogo se os sujeitos amam o mundo e as pessoas, uma vez que a construção do bem comum exige a presença na vida pública com intenso amor, com disposição e vontade, com o desejo de tramar a vida em comunidade.

Amor, para que o diálogo se efetue, deve se configurar na coragem e no compromisso com as causas de libertação das pessoas, historicamente, excluídas. O diálogo só é possível quando se ama a vida e as pessoas. Outra condição apresentada por Freire para garantia do diálogo é saber-se humilde, sem atos arrogantes, para que, junto com os que necessitam de mais atenção, criar e recriar de forma permanente a vida. Aqui, Paulo Freire traz presente a alteridade, o sentir e o se comunicar com o outro, o perceber inteiramente os pares, aqueles com os quais tecemos a existência.

Assim, didaticamente, o diálogo se materializa na situação concreta da vida dos envolvidos em qualquer ação educacional, por meio das aspirações do grupo, das vontades, do concreto, dos problemas reais que precisam de respostas. Desse modo, torna-se viável o refletir e o agir, o pensar e o fazer, de forma inseparável. O agir no coletivo e com o coletivo para a trama da vida humana solidária, cooperativa para o mundo que, sob o manto do direito e da dignidade, inclua a todos.

Por essa razão que o pensamento freireano é importante neste momento, pois ele ilumina as sombras que se abatem na política, nas instituições e na educação brasileira. Como diz Buella (2006, p. 211), o pensamento traz "as ordens invisíveis de uma convivência possível entre os homens". É um pensamento que ajuda a incluir, a desvelar aquele que corrompe e que oprime. Uma democracia sem o diverso, sem a possibilidade do diálogo entre os diferentes, sem a liberdade de expressão em sua natureza, marcha para um sistema totalitário. 


\section{A educação em direção à liberdade e os riscos do autoritarismo}

Entendemos a educação como permanente esforço das pessoas em se constituírem na história, um encontro consigo mesmas e na plenitude da vida humana, que se configura nas relações coletivas ou comunitárias. Esse encontro se dá pela liberdade que as pessoas vão assumindo em cada sociedade. Desse maneira, do ponto de vista freireano, o movimento em direção à liberdade define o processo educativo com o sentido de libertação, uma vez que a educação é libertadora quando os indivíduos são capazes de dialogar em seu grau maior de autonomia.

Toda a reflexão pedagógica freireana centra-se na pessoa, concretamente, na pessoa do oprimido, aquela sem voz, sem consciência, sem vez em sua cidadania. Freire acredita que a educação tem como finalidade a prática da liberdade da pessoa em ação e da sua intervenção criadora no mundo. Mediante uma pedagogia humanizadora espera-se que os oprimidos ultrapassem o estado de "quase coisa", visto que as tipologias de opressão que o Brasil vivencia representam a própria desumanização como distorção da "vocação de ser mais" (FREIRE, 2003b, p. 61). Nesse sentido, toda forma de opressão tem a sombra autoritária que moldura as ações.

O autoritarismo, na perspectiva freireana, define o privilégio da autoridade presente que assume ações que vão de encontro à liberdade e que coagem expressões de diálogo e da ação. Na convicção de Freire (2003a, p. 89), “o autoritarismo é a ruptura em favor da autoridade contra a liberdade e a licenciosidade, a ruptura em favor da liberdade contra a autoridade". A negação da liberdade e do diálogo emudece a educação, retirando-lhe seu sentido maior de humanização. Essa rejeição acabrunha seus destinatários, ofuscando-os na "vocação de ser mais". É da natureza da educação a liberdade e as diversas formas de sua manifestação. Ao contrário, uma educação do silenciamento, da obediência obsequiosa, da reprodução social que atende aos anseios do mercado e que é perpetrada pelos discursos de ódio, no dizer de Catani (2019, p. 38), aniquila as experiências formativas e de autonomia, pois "ela não apenas projeta para o futuro, mas tem em seu próprio núcleo a barbárie".

O mando, sob os auspícios do governante tirano, torna-se instrumento de subordinação e de silenciamento. Não é de hoje que o mandatismo se configura na história dos governantes brasileiros. Em Freire (2003a, p. 92) “o mandatismo é exatamente esse gozo irrefreável e desmedido pelo mando", que, sob a forma da autoridade, se torna rígido e não conta com nenhuma dialogicidade. Nessa linha de pensamento, Schwarcz (2019, p. 63) ao estudar o autoritarismo brasileiro, vaticina sobre a raiz do autoritarismo político atrelado ao mando 
oligárquico colonial rural, que atravessou a nossa história e se adaptou nas mais variadas configurações políticas, emplacando, finalmente, os novos estilos de governabilidade. Para a referida autora, corremos perigo quando não rompemos "com a figura do pai político - agora uma espécie de chefe virtual, que fala em nome e no lugar dos filhos e dependentes -, do herói destacado e excepcional, do líder idealizado”. Esse herói, como todo ente idealizado, supre as lacunas humanas e se tangencia nas massas.

Sobre esse entendimento, Bignotto (2001, p. 39) afirma que as massas só se tornam ativas quando conduzidas por um líder, "que lhes empresta um rosto e confere um sentido para suas ações”. Para Arendt (1978, p. 406), “a principal característica do homem da massa não é a brutalidade nem a rudeza, mas o seu isolamento e a sua falta de relações sociais normais". Ao que tudo indica, o projeto autoritário que vem se desenvolvendo no governo de Bolsonaro, aponta para o isolamento das pessoas e para minimizar as relações sociais e tudo o que advir delas.

Vale salientar que esses movimentos autoritários que pairam sobre o Brasil de hoje minam a ação dos cidadãos, tornando-os parte de uma massa de supérfluos, quase que uma escória, um refugo humano. Os ódios perpetrados nas últimas campanhas eleitorais e estimulados pelos seguidores do atual governo apresentam-se como um alerta de que uma onda nefasta de intimidação e de perseguição já se espalhada no país.

Como bem definiu Ansart (2004, p. 24), “o problema dos ódios públicos apresenta-se, portanto, sob formas diversas, confusas, numa obscuridade profunda". Cria um ressentimento entre os bons e os maus, entre "nós" e "eles", os inteligentes e os ignorantes, os que trabalham para suportar os que vivem do Bolsa Família, os famigerados, finalmente. Esse tipo de sistema promove o ressentimento dos excluídos, no dizer do mesmo autor (2004, p. 27), é "facilmente compartilhado, mantém as populações vivendo na desintegração da comunidade e em situação de atomização social, em um total ceticismo em relação ao político, em uma obediência passiva destituída de consentimento".

O problema é que, hoje, vemos em toda a parte, sendo noticiados, diariamente, elementos do pensamento autoritário. O imperialismo da expansão do capitalismo tem sufocado as grandes democracias em nome de um modelo de acumulação capitalista desproposital, que está acabando com planeta e, consequentemente, com os seus habitantes. A sobrevivência dos elementos autoritários se torna uma ameaça à democracia e ao Estado Democrático de Direito. Uma ameaça ao próprio pensamento de continuar a pensar e a lutar em prol de uma educação democrática e da liberdade de ensinar. Nesse sentido, importantes são as reflexões organizadas 
por Cássio (2019) sobre educação e contra a barbárie educacional que começou a se instalar no Brasil a partir de 2016, com o golpe do impeachment contra o governo de Dilma Rousseff.

Frente à experiência de apatia cívica, de ausência de ética na política, do descuido com o cidadão e da fragilidade na democracia, reforça-se a ideia de que na política não se tem mais esperança, pois os conflitos foram armados e precisamos de alguém para geri-los. O vazio existencial político pode ser um forte apelo para que as raposas acabem por sair de suas tocas e se autoproclamem solucionadoras dos conflitos e salvadoras do povo. Lembremo-nos que o ditador alemão Adolfo Hitler, para chegar ao poder, não foi por meio de um golpe, mas pela vontade do povo germânico. Os regimes autoritários ou totalitários se beneficiam das ideias, como ideologia, do apoio popular e da polarização das massas como meio de amplificar o terror.

Essas ideias são encadeadas nos acontecimentos como se eles tivessem a mesma posição lógica que se adotou na exposição como explicação. A ideologia do totalitarismo tem aversão à contradição, uma espécie de tirania da lógica como componente subserviente à ideia dominante. A partir daí todas as outras pessoas devem se orientar para elaborar o seu pensamento. O cerne do totalitarismo é fazer acreditar numa mentira descarada em nome de uma ideia única: nisso consiste a ideologia totalitária. Fundamenta-se na mentira que se encontra em seu começo.

Como bem alerta Souki (2006, p. 62), ao se referir às leis e aos movimentos dentro do totalitarismo: "sua eficácia assustadora depende, em grande parte, da suprema liberdade de seu chefe, que não é obrigado a respeitar nenhuma regra fixa, nem mesmo suas próprias decisões e declarações anteriores". Esse extraordinário contrassenso e cinismo se encontra, hoje, em nosso governante maior e seus comandados.

Na compreensão de Arendt (1978), a violência imposta às pessoas, por meio do sistema totalitário, é de que ela não pertence a esse mundo. A desolação é tida como efeito de uma ideologia imposta à pessoa, de que se ela não pensar e agir como o sistema impõe ela está desfiliada. Quando vemos as grandes redes de comunicação se unindo para transmitir uma só mensagem, uma só verdade à população, isso é próprio da propaganda totalitária.

Como ideia única, essa ideologia elimina a diversidade de ideias, configurando-se, assim, o terror que visa impossibilitar a resistência e intimidar, num primeiro momento, aqueles que insistem em pensar diferente do poder dominante. Depois vêm os instrumentos de perseguição e de tortura. Uma vez a pessoa não podendo exercer mais a sua pluralidade humana, só lhe resta o isolamento.

Sob essa perspectiva, Vallée (2003, p. 65) vê nos sistemas totalitários o isolamento como a tentativa de desenraizamento da pessoa à sua pátria, tornando-a inútil. "[...] $\mathrm{O}$ 
Totalitarismo não é a exacerbação do político, é a sua destruição". Toda negação à vida, sobretudo à vida pública, é contrária à política, consequentemente, acabando por desembocar na tirania e na barbárie, desumanizando o convívio humano, por meio de ações em que se negue as diferenças e tudo o que for diverso, se aponta para um sistema autoritário. Esse sistema fechado em si mesmo, sem abertura ao diálogo e sem acolhimento aos movimentos sociais e representações civis, as dimensões políticas autoritárias ameaçam a democracia.

Uma sociedade que prega a conformidade, o isolamento e o cumprimento de comportamentos previsíveis estabelece uma espécie de totalitarismo em meio à sobrevivência individual. Nessas circunstâncias, a novidade não pode aparecer em âmbito político, e a liberdade fica sob ameaça. Sem a promessa de liberdade, o homem se ofusca na realidade do domínio político (CORREIA, 2008).

Sobre a dimensão da novidade ou do renascimento em política, Arendt (2010, p. 10) assinala como um "novo começo inerente ao nascimento pode se fazer sentir no mundo somente porque o recém-chegado possui a capacidade de iniciar algo novo, isto é, de agir”. Essa novidade ligada à ação permite a fundação dos corpos políticos que se imbricam na pluralidade humana, espaço por natureza das divergências humanas. Essa fundação só se permite graças aos novos seres humanos que continuamente aparecem no mundo por causa do nascimento (ARENDT, 1992). Isso nos garante uma ação nova, porque somos humanos e iguais, de tal modo, bem verdade, que ninguém tem a sua réplica. Também é verdade, e somos da mesma opinião de Emcke (2020, p. 185), de que "ninguém define o 'nós' sozinho. Ele surge quando as pessoas agem juntas e desaparece quando elas se desagregam”.

Quando a educação contribui para o embaraçamento dessa situação de posição acrítica e alienada, ela corrobora com as deploráveis manifestações de nossas, cada vez piores, condições de existência. Fecha-se no próprio mundo agonizante das angústias e agruras do ser humano. O grande desafio, hoje, é o de ampliar as margens do pensamento crítico e o de valorizar o ser humano frente aos limites que as políticas educacionais vêm apresentando como deformação autoritária do poder.

Nesse sentido, Assy (2015, p. 23-24) afirma que o sistema totalitário "trouxe a excepcionalidade das situações limítrofes, forçando a divisória que separa a responsabilidade política da pessoal". A tentativa, por parte, do governo atual em arrefecer o engajamento social, por meio da comunidade, demonstra o isolamento pessoal diante dos acontecimentos.

No Estado Democrático de Direito, a política assume um papel da pluralidade que deve ganhar terreno frente ao não diálogo instalado pelas ideologias autoritárias ou totalitárias. As posições não são determinadas pelo diálogo consigo mesmo; importa abrir-se ao diálogo com 
os outros e com os diferentes. Os lampejos que os fenômenos totalitários trazem para o país, em nossos dias, evidenciam o desmoronamento do espaço democrático de direito, promovido por um chefe máximo de Estado e seus seguidores, pois de acordo com o constitucionalista Ávila (2019, p. 12) o Estado, ao violar a dignidade do ser humano, quando o manipula ou coage, impede-o de manifestar livremente a sua vontade e de exercer "autonomamente seu poder de decidir quais propósitos quer conceber, quais responsabilidades pretende assumir e com quais consequências deseja contar", pois, para o referido autor, o Estado Democrático de Direito deveria dar "condições essenciais para a preservação e promoção de uma vida digna e livre" (ÁVILA, 2019, p. 19).

A destruição paulatina dos direitos do cidadão, a agonia do jurídico como condição primordial para garantir os direitos constitucionais já não são pilares que garantem a credibilidade ao povo brasileiro. A destruição dos direitos civis garantidos na Constituição Brasileira e demais códigos de leis se amplia pela omissão ou mesmo ação deliberada dos agentes do Estado, que ao invés de cumprir suas atribuições e responsabilidades em defesa do povo e da plena democracia, acaba por desempenhar o papel de tirano perseguidor. Já não se sabe quem é o perseguido e o perseguidor, o algoz e a vítima no sistema totalitário. Como afirma Souki (2006, p. 52), “o totalitarismo permanece uma noção genérica que recobre uma grande variedade de elementos, daí a impossibilidade de se fornecer um critério não ambíguo à aplicação deste conceito".

De qualquer forma, os elementos autoritários já estão postos, e tudo leva a crer que as políticas voltadas ao sistema educacional brasileiro estão sob o espectro sombrio do projeto totalitário. Contrariamente, quando um país oferece educação voltada para o indivíduo em sua inteireza, com menos competitividade, silenciamento e exclusões, ele diz qual o tipo de Estado que ele quer ter.

Quando a educação tem suas raízes fincadas no horizonte da equidade, da amorosidade com as pessoas e da plena cidadania, ela se torna humanizadora, pois se pressupõe que o diálogo é o que permeia toda conduta humana. Com isso, a educação libertadora, sob a égide do pensamento de Paulo Freire, pode nos ancorar, sem sombra de dúvidas, em princípios éticos, para alcançarmos os mais altos graus da escala da evolução humana. 


\section{Referências}

ABRUCIO, Fernando. Contra escola sem sentido. In: AÇÃO Educativa Assessoria, Pesquisa e Informação (org.). A ideologia do movimento Escola sem Partido: 20 autores desmontam o discurso. São Paulo: Ação Educativa, 2016. p. 59-64.

ANSART, Pierre. Hannah Arendt: a obscuridade dos ódios públicos. In: DUARTE, André; LOPREATO, Cristina; MAGALHÃES, Marion Brepohl de (orgs.). A banalização da violência: a atualidade do pensamento de Hannah Arendt. Rio de Janeiro: Relume Dumará, 2004. p. 17-33.

ARAÚJO, Maria do Socorro Sousa de; CARVALHO, Alba Maria Pinho de. Autoritarismo no Brasil do presente: bolsonarismo nos circuitos do ultraliberalismo, militarismo e reacionarismo. Katálysis, Florianópolis, v. 24, n. 1, p. 146-156, jan./abr. 2021. Disponível em: https://doi.org/10.1590/1982-0259.2021.e75280 Acesso em: 20 abr. 2021.

ARENDT, Hannah. O sistema totalitário. Lisboa: Publicações Dom Quixote, 1978. (Universidade Moderna; 60).

ARENDT, Hannah. Entre o passado e o futuro. 3. ed. São Paulo: Perspectiva, 1992.

ASSY, Bethania. Ética, responsabilidade e juízo em Hannah Arendt. São Paulo: Perspectiva; Instituto Norberto Bobbio, 2015. (Estudos; 334).

ÁVILA, Humberto. Constituição, liberdade e interpretação. São Paulo: Malheiros, 2019.

BIGNOTTO, Newton. O Totalitarismo hoje? In: AGUIAR, Odílio Alves [et. al.] (orgs.). Origens do Totalitarismo: 50 anos depois. Rio de Janeiro: Relume Dumará; Fortaleza: Secretaria da Cultura e Desporto, 2001. p. 37-46. (Outros Diálogos; 7).

BUELLA, Laura. ¿Qué significa pensar políticamente? In: BIRULÉS, Fina (comp.). Hannah Arendt: el orgullo de pensar. Barcelona: Editorial Gedisa, 2006. p. 177-234.

CARA, Daniel. O Programa "Escola sem Partido" quer uma escola sem educação. In: AÇÃO Educativa Assessoria, Pesquisa e Informação (org.). A ideologia do movimento Escola sem Partido: 20 autores desmontam o discurso. São Paulo: Ação Educativa, 2016. p. 43-48.

CÁSSIO, Fernando (org.). Educação contra a barbárie: por escolas democráticas e pela liberdade de ensinar. São Paulo: Boitempo, 2019. (Tinta Vermelha).

CATANI, Carolina. Educação e empreendorismo da barbárie. In: CÁSSIO, Fernando (org.). Educação contra a barbárie: por escolas democráticas e pela liberdade de ensinar. São Paulo: Boitempo, 2019. p. 33-39. (Tinta Vermelha).

CHAUI, Marilena. Cultura Popular e Autoritarismo - Uma sociedade autoritária. In: CHAUI, Marilena. Manifestações ideológicas do autoritarismo brasileiro. Belo Horizonte: Autêntica; São Paulo: Fundação Perseu Abramo, 2014.

CASTELLS, Manuel. "Brasil já não é democracia”, diz o sociólogo Manuel Castells. [Entrevista concedida à Helena Celestino]. Valor Econômico, São Paulo, $1^{\circ}$ maio 2021. Eu \& 
Notícia. Disponível em: https://valor.globo.com/eu-e/noticia/2021/05/01/brasil-ja-nao-edemocracia-diz-o-sociologo-manuelcastells.ghtml. Acesso em: $1^{\circ}$ maio 2021.

CORREIA, Adriano. O significado político da natalidade: Arendt e Agostinho. In:

CORREIA, Adriano; NASCIMENTO, Mariangela (orgs.). Hannah Arendt: entre o passado e o futuro. Juiz de Fora, MG: Ed. UFJF, 2008. p. 15-34.

CORTINA, Adela. Aporofobia, el rechazo al pobre: un desafío para la democracia. Barcelona: Paidós, 2017. (Paidós Estado y Sociedad).

CUSTÓDIO, Tulio. Ninguém viu, ninguém vê: comentários sobre o estado da violência na atual democracia (de poucos). In: PINHEIRO-MACHADO, Rosana; FREIXO, Adriano de (orgs.). Brasil em transe: Bolsonarismo, Nova Direita e Desdemocratização. Rio de Janeiro: Oficina Raquel, 2019. p. 120-143. (Pensar Político).

DIAS, Antonio Francisco Lopes. A democracia como vítima do golpe tragicômico de 2016 no Brasil. Argumentos, Fortaleza, ano 10, n. 19, jan./jun. 2018.

EMCKE, Carolin. Contra o ódio. [S.l.]: Âyiné, 2020. (Biblioteca).

FERNANDES, Florestan. A Revolução Burguesa no Brasil. Rio de Janeiro: Zahar, 1975.

FREIRE, Paulo. Educação como Prática de Liberdade. Rio de Janeiro: Paz e Terra, 1967.

FREIRE, Paulo. Pedagogia da autonomia: saberes necessários à prática educativa. 28. ed. Rio de Janeiro: Paz e Terra, 2003a.

FREIRE, Paulo. Pedagogia do oprimido. 37. ed. Rio de Janeiro: Paz e Terra, 2003b.

GADOTTI, Moacir. A escola cidadã frente ao "Escola Sem Partido". In: AÇÃO Educativa Assessoria, Pesquisa e Informação (org.). A ideologia do movimento Escola sem Partido: 20 autores desmontam o discurso. São Paulo: Ação Educativa, 2016. p. 149-160.

KORYBKO, Andrew. Guerras híbridas: das revoluções aos golpes. São Paulo: Expressão Popular, 2018.

LEVITSKY, Steven; ZIBLATT, Daniel. Como as democracias morrem. Rio de Janeiro: Zahar, 2018.

MOUNK, Yascha. O povo contra a democracia: por que nossa liberdade corre perigo e como salvá-la. São Paulo: Companhia das Letras, 2019.

SCHWARCZ, Lilia Moritz. Sobre o autoritarismo brasileiro. 3. reimp. São Paulo: Companhia das Letras, 2019.

SILVA, Ederson Duda. As bases da nova direita: estudo de caso do Movimento Brasil Livre na cidade de São Paulo. Conversas \& Controvérsias, Porto Alegre, v. 5, n. 1, p. 75-95, jan.jun. 2018. 
SOUKI, Nádia. Hannah Arendt e banalidade do mal. Belo Horizonte: Ed. UFMG, 2006. (Humanitas).

SOUZA, Jessé. A elite do atraso: da escravidão à Lava Jato. São Paulo: Leya, 2017.

VALLÉE, Catherine. Hannah Arendt: Sócrates e a questão do totalitarismo. Lisboa: Instituto Piaget, 2003. (Pensamento e Filosofia; 97).

XIMENES, Salomão. O que o direito à educação tem a dizer sobre "escola sem partido"? In: AÇÃO Educativa Assessoria, Pesquisa e Informação (org.). A ideologia do movimento Escola sem Partido: 20 autores desmontam o discurso. São Paulo: Ação Educativa, 2016. p. 49-58. 